\title{
Cardiovascular and Thermal Response to Dry-Sauna Exposure in Healthy Subjects
}

\author{
Pawel Zalewski, ${ }^{1}$ Monika Zawadka-Kunikowska, ${ }^{1}$ Joanna Słomko, ${ }^{1}$ Justyna Szrajda, \\ Jacek J. Klawe, ${ }^{1}$ Malogorzata Tafil-Klawe, ${ }^{3}$ and Julia Newton ${ }^{4}$ \\ ${ }^{1}$ Department of Hygiene and Epidemiology, Faculty of Health Sciences Ludwik Rydygier Collegium Medicum in Bydgoszcz, Nicolaus \\ Copernicus University in Torun, M. Sklodowskiej-Curie 9, 85-094 Bydgoszcz, Poland \\ ${ }^{2}$ Department of Health Care Politics and Social Care, Faculty of Health Sciences Ludwik Rydygier Collegium Medicum in Bydgoszcz, \\ Nicolaus Copernicus University in Torun, Sandomierska 16, 85-094 Bydgoszcz, Poland \\ ${ }^{3}$ Department of Human Physiology, Faculty of Medicine Ludwik Rydygier Collegium Medicum in Bydgoszcz, Nicolaus Copernicus \\ University in Torun, Ludwik Rydygier Collegium Medicum in Bydgoszcz, Karłowicza 24, 85-092 Bydgoszcz, Poland \\ ${ }^{4}$ Institute for Ageing and Health, The Medical School, Newcastle University, Framlington Place, Newcastle-upon-Tyne NE2 4HH, UK
}

Correspondence should be addressed to Pawel Zalewski; p.zalewski@cm.umk.pl

Received 4 August 2014; Accepted 23 September 2014; Published 8 October 2014

Academic Editor: Marco Guazzi

Copyright (C) 2014 Pawel Zalewski et al. This is an open access article distributed under the Creative Commons Attribution License, which permits unrestricted use, distribution, and reproduction in any medium, provided the original work is properly cited.

\begin{abstract}
Dry-sauna is a strong thermal stimulus and is commonly used all over the world. The aim of this experiment was to comprehensively analyse cardiovascular and autonomic changes that result from an increase in core body temperature during sauna bath. The study included 9 healthy men with mean age $26.7 \pm 3.0$ years and comparable anthropomorphical characteristics. Each subject was exposed to one 15 -minute session of dry-sauna treatment at $100^{\circ} \mathrm{C}$ and $30-40 \%$ humidity. The autonomic and baseline cardiovascular (i.e., hemodynamic and contractility) parameters were measured noninvasively with Task Force Monitor. Cardiovascular autonomic functions were assessed using baroreceptor reflex sensitivity (BRS) and spectral analysis of heart rate (HRV) and blood pressure (BPV) variability. Measurements were performed four times, at the following stages "before sauna," "after sauna," "sauna +3 h," and "sauna +6 h." The first recording constituted a baseline for the subsequent three measurements. The changes in core body temperature were determined with the Vital Sense telemetric measurement system. Results show that exposure to the extreme external environmental conditions of dry-sauna does not compromise homeostasis in healthy persons. The hemodynamic changes induced by heating are efficiently compensated by the cardiovascular system and do not exert negative effects upon its short-term regulatory potential.
\end{abstract}

\section{Introduction}

Sauna constitutes one of the most popular and most extensively studied forms of whole-body thermal treatment. The idea of sauna originated in Scandinavian countries over a century ago and quickly gained popularity and it is now widely used worldwide [1-3]. The conditions of a sauna are determined by a combination of efficiency of thermoregulatory response, age, gender, and the cardiorespiratory performance of an individual $[4,5]$, together with the tradition of a given country. While high temperatures $\left(90-100^{\circ} \mathrm{C}\right)$ and low humidity $(10-15 \%)$ are typically used in Germany, Turkish sauna baths are completely different $\left(70-80^{\circ} \mathrm{C}, 40 \%\right)$. In turn, infrared (IR) and far-infrared (FIR) saunas, with $45-60^{\circ} \mathrm{C}$ temperatures, are more popular in Canada $[3,6]$. Recently, this latter form of dry sauna has gained popularity, described as a form of biological renewal because of a cardiovascular strain associated with the treatment [1].

The term "sauna," used in medical literature, is derived from a traditional Finnish steam bath in a room heated by an electric stove. Overheating of the body takes place in a wooden room with temperatures approaching $70-100^{\circ} \mathrm{C}$ and low, $10-20 \%$ humidity levels. Usually, sauna duration lasts between 5 and 15 minutes [2, 3, 7]. Each heating session is followed by cooling down of the body under cold shower or in a pool with cold water. One complete treatment comprises 
two or three heating/cooling down cycles, with a restitution period when fluid repletion is recommended $[8,9]$. Sauna is recommended for persons with musculoskeletal, cardiovascular, and respiratory disorders. Moreover, it can be used as a form of adjunct treatment for obesity, depression, chronic pain, and chronic fatigue syndrome [7, 10-12]. The effects of sauna bath in patients with cardiovascular conditions are well established and exhaustively reported $[1,5,6,13,14]$. Sauna treatment proved to be a well-tolerated and safe procedure for most healthy persons and individuals with congenital and chronic diseases of the heart [5, 13-17]. The risk of acute coronary syndrome or sudden cardiac death during sauna bath is lower than those during other activities of daily living [18], and the level of cardiovascular strain associated with sauna treatment is similar to that during a light physical work [13]. Moreover, sauna treatment has been postulated to exert a potential therapeutic effect in patients with primary arterial hypertension [5, 14]. Regular sauna treatment of patients with chronic heart failure can be associated with a decrease in arterial blood pressure and an increase in the left ventricular ejection fraction $[7,15,16]$. Sudden cardiac death constitutes the most serious but very rare adverse effect of sauna bath. This complication has been most often reported in individuals with latent cardiovascular conditions, patients treated with diuretics, and persons who consumed alcohol or used extreme heating/cooling down conditions during sauna bath [2,7].

Exposure to heat induces a number of cardiovascular and thermoregulatory changes that protect the body against overheating. Physiological responses to thermal stress involve an array of reactions aimed at efficient dispersion of excess heat. Cardiovascular responses to thermal stimulation during sauna bath have been a subject of extensive research $[2,19]$. In contrast to previous studies, the aim of this experiment was to comprehensively analyse cardiovascular and autonomic changes that result from an increase in core body temperature during sauna bath. The use of modern techniques of measurement enabled us to analyse the dynamics of regulatory and adaptive processes being controlled by the autonomic nervous system.

\section{Material and Methods}

2.1. Subjects. The study included 9 healthy young male volunteers who satisfied all the inclusion criteria, that is, lacked any organic disease or functional disorder of the cardiovascular and autonomic nervous system examined with a short form for autonomic function testing. Prior to the exposure, each of the participants was examined by a physician specialized in cardiac rehabilitation. The subjects did not use any medications that could interfere with the cardiovascular or autonomic function. Prior to the sauna exposure, and during the postsauna period, the participants remained in a dedicated faculty for biological renewal procedures that included an air-conditioned room with constant ambient temperature and humidity, and their activity was limited to a necessary minimum; they were allowed only to walk across the room or watch TV and were supervised by the research team. Subjects
TABLE 1: Basic characteristics of the study subjects.

\begin{tabular}{lcc}
\hline Characteristic & Subjects $n=9$ & Range \\
\hline Age (years) & $26.7 \pm 3.0$ & $25-32$ \\
Body height $(\mathrm{m})$ & $1.7 \pm 0.02$ & $1.76-1.85$ \\
Body weight $(\mathrm{kg})$ & $81.5 \pm 11.0$ & $62.0-100.0$ \\
Body Mass Index $\left(\mathrm{kg} / \mathrm{m}^{2}\right)$ & $25.2 \pm 2.7$ & $20.0-30.0$ \\
Body Surface Area $\left(\mathrm{m}^{2}\right)$ & $2.0 \pm 0.1$ & $1.94-2.11$ \\
\hline
\end{tabular}

did not participate in any activities which could influence natural core body temperature balance. All subjects were nonsmokers and were also instructed to refrain from caffeine, alcohol ingestion, and intensive physical activity on the day of investigation and ate a light breakfast only. Food intake during the experiment was also controlled by research staff. During the whole experiment, subjects were allowed to drink only water and had two light, thermoneutral meals between "after sauna"-"sauna $+3 \mathrm{~h}$ " and "sauna $+3 \mathrm{~h}$ "-"sauna $+6 \mathrm{~h}$ " stages; first water consumption was allowed two hours after telemetric capsule intake.

The protocol of the study was approved by the Local Bioethics Committee of the Collegium Medicum in Bydgoszcz, Nicolaus Copernicus University in Torun, and written informed consent was obtained from all the participants. Basic characteristics of the study subjects are summarized in Table 1.

2.2. Cardiovascular and Autonomic Parameters. The autonomic and baseline cardiovascular parameters were measured noninvasively using the Task Force Monitor system (TFM, CNSystems, Medizintechnik, Graz, Austria). The fact that TFM determines and records biological signals in a completely accurate and noninvasive manner, in a beat-tobeat mode, represents the principal advantage of this system during the examination of dynamic changes in a short-term cardiovascular regulation. TFM comprises devices for continuous (contBP) and oscillometric (oscBP) blood pressure measurement, electrocardiograph (EKG), and impedance cardiograph (IKG) $[18,20,21]$. Cardiovascular autonomic functions were assessed using baroreceptor reflex sensitivity (BRS), spectral analysis of heart rate (HRV), and blood pressure (BPV) variability in an adaptive autoregressive model (AAR) $[22,23]$. Spontaneous sensitivity of arterial baroreceptors was determined with a sequential method for shortterm sequences of blood pressure variability. This method is based on an identification of at least 3 consecutive heartbeats that are defined as a single sequence and characterized by an elongation of R-R intervals (RRI) preceded by a gradual increase in systolic blood pressure (sBP) or by a shortening of the R-R intervals (RRI) preceded by a gradual decrease in the systolic blood pressure (sBP) [24].

Biological signals recorded by TFM were registered continuously for a minimum of five minutes after acquired all signals stabilization, at four time points referred to as "before sauna," "after sauna (no longer than $15 \mathrm{~min}$ )," "sauna+ $3 \mathrm{~h}$," and "sauna $+6 \mathrm{~h}$." The first recording constituted a baseline for the subsequent three measurements. The tests 
were conducted under standardized conditions for functional examination of the autonomic nervous system, after a $10 \mathrm{~min}$ restitution period aimed at the stabilization of cardiovascular parameters of an examined individual. All the measurements were taken during the same time of the day, in a quiet room with stable neutral temperature $\left(23^{\circ}-24^{\circ} \mathrm{C}\right)$ and air humidity $[25,26]$.

2.3. Core Body Temperature. The changes in core body temperature were determined with Vital Sense telemetric measurement system (Equivital, Hidalgo Ltd., Cambridge, UK; formerly: Philips Respironics; Mini Mitter Co. Inc., Bend Oregon, USA). The Vital Sense system for telemetric measurement of core body temperature is comprised of two components: a portable monitor and a telemetric capsule (CBTC). The function of the system is based on a registration of radiofrequency signal emitted by a sensor of core body temperature, that is, by the telemetric capsule. The participants were asked to swallow the capsule with a small amount of warm water. After about one minute, CBTC started registration of changes in core body temperature. Mean values of all measurements taken during each 1-minute interval were stored in the monitor's memory. The continuous temperature recordings were divided into 10-minute segments, separated by 5 -minute intervals. The segments that corresponded to consecutive measurements taken with TFM were subjected to a comparative analysis $[27,28]$. To analyze the effect of thermal stress on core body temperature, registration of the latter started at least two hours prior to the sauna exposure.

Moreover, the method of measurement was not associated with any discomfort of our participants and thus did not interfere with the recorded values of core body temperature [27].

2.4. Sauna Exposure. The participants were subjected to one 15 -minute session of dry sauna treatment at $100^{\circ} \mathrm{C}$ and $30-40 \%$ air humidity. The exposure was preceded by an acclimatization at a neutral temperature $\left(23^{\circ}-24^{\circ} \mathrm{C}\right)$. The treatment was not followed by cooling down under a cold shower, in order the exclude the confounding effect of the latter procedure on the dynamics of temperature changes. Furthermore, the participants were asked to refrain from consuming alcohol and coffee, smoking tobacco, and performing intensive physical exercise during 24 hours preceding the examination and treatment [7]. All sauna exposures took place at the same time of day to account for circadian rhythm.

2.5. Statistics. All data are presented as means \pm SD. Normal distribution of the study variables was verified with the Shapiro-Wilk test. Levane's test was used to check the homogeneity of variances in the analysed samples. The results were compared with ANOVA and Tukey post-hoc test, or with Friedman's ANOVA test and Dunn's post-hoc test if appropriate. The results of the tests were considered significant at $\alpha=0.05$.

\section{Results}

Heart rate (HR) and baroreceptor reflex sensitivity (BRS) were the only hemodynamic and cardiovascular parameters that showed significant changes (resp., $P=0.0120$ and $P=0.0457)$ in response to dry sauna treatment. The thermal treatment showed a significant increase in HR that was observed immediately after the exposure and 3 hours thereafter. In contrast, a significant decrease in BRS was observed both immediately after the sauna bath and 3 hours later. Six hours after the exposure both HR and BRS normalized to their pretreatment values (Table 2).

A significant increase in Heather index (HI) values was observed 3 and 6 hours after the dry sauna bath $(P=$ $0.0181)$. In turn, a significant decrease in the left ventricular ejection time (LVET) was documented immediately after the treatment, as well as 3 and 6 hours thereafter $(0.0181)$. Furthermore, a significant decrease in the preejection period (PEP) was observed 3 and 6 hours postexposure $(P=0.0068)$ (Table 3).

The sauna treatment resulted in a significant increase in core body temperature, which reached its peak values immediately after the exposure and gradually normalized 3 and 6 hours thereafter (Table 4).

The relationships between hemodynamic and cardiovascular parameters, core body temperature prior to the dry sauna treatment, and at various stages after the procedure are presented schematically in Figure 1.

The dry sauna bath resulted in a significant decrease in heart rate variability parameters: HR-RRI $(P=0.0313)$ and PSD-RRI $(P=0.0412)$. Both the spectral parameters normalized no earlier than 6 hours after the procedure. The abovementioned changes were reflected by a significant increase in the sympathetic-parasympathetic balance ratio of the heart rate spectrum $(P=0.0483)$, observed immediately after the sauna bath and 3 hours thereafter. Moreover, a significant increase in the normalized low-frequency component of diastolic blood pressure spectrum (LFnu-dBP, $P=$ 0.0438 ) was observed up to 3 hours after the treatment, along with a significant decrease in the high-frequency components (HFnu-dBP, $P=0.0438$ and HF-dBP, $P=0.0238$ ). All these changes resulted in a concomitant increase in the sympathetic-parasympathetic balance ratio of the diastolic blood pressure spectrum $(P=0.0029)$. Finally, a significant increase in the normalized low-frequency component of systolic blood pressure spectrum (LFnu-sBP, $P=0.0273$ ) was documented immediately after the sauna bath, along with a concomitant increase in the sympathetic-parasympathetic balance ratio of the systolic blood pressure spectrum $(P=$ 0.0439) (Table 5).

The relationships between heart rate and blood pressure variability parameters and core body temperature prior to the dry sauna treatment and at various stages after the procedure are presented schematically in Figure 2.

\section{Discussion}

Our study showed that a single exposure of healthy young men to conditions associated with the Finnish sauna bath 


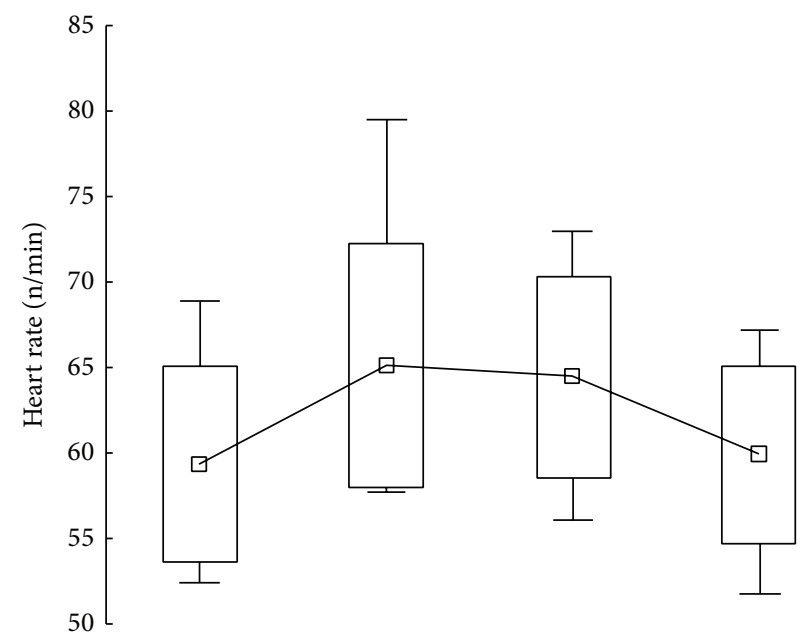

(a)

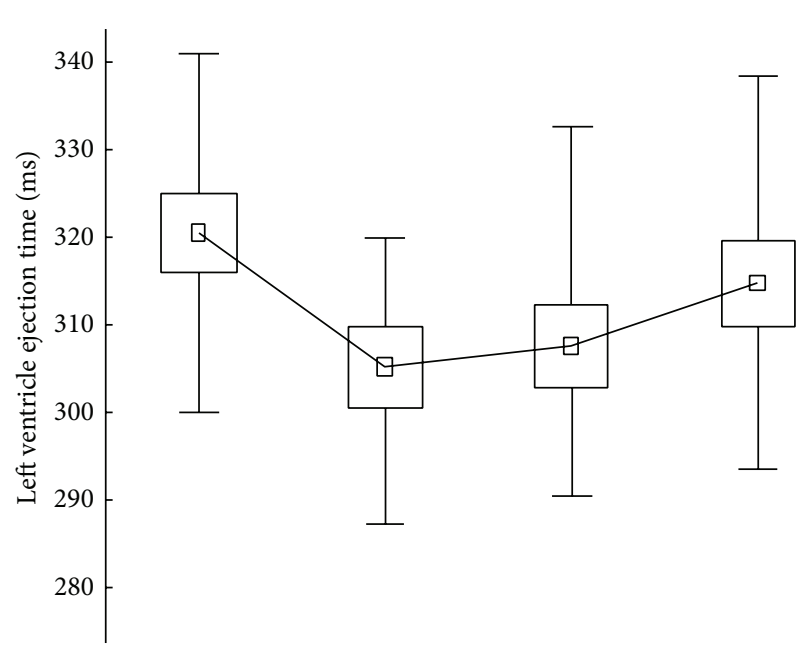

(c)

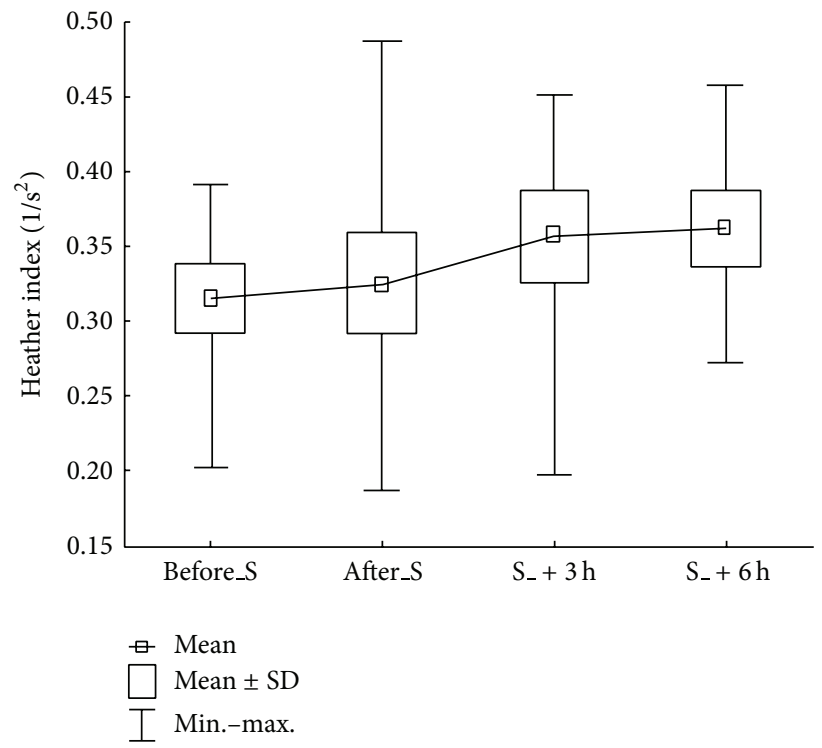

(e)

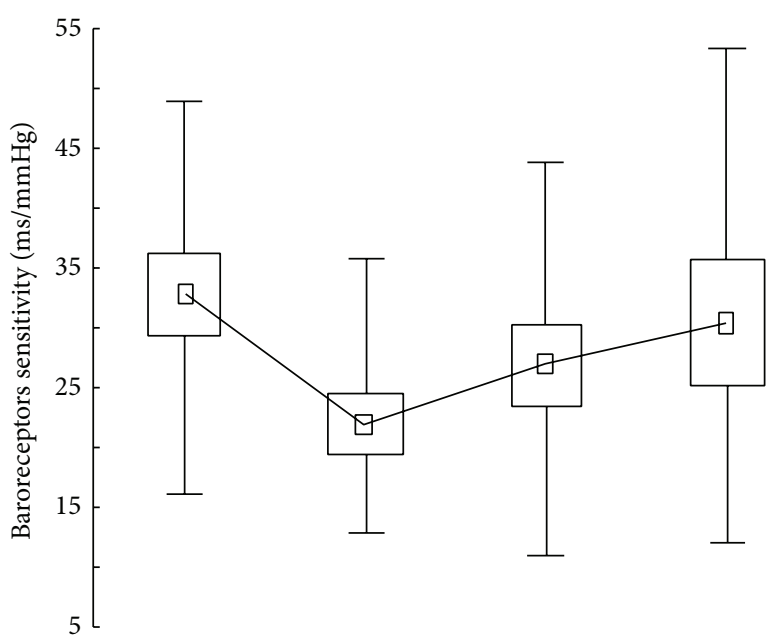

(b)

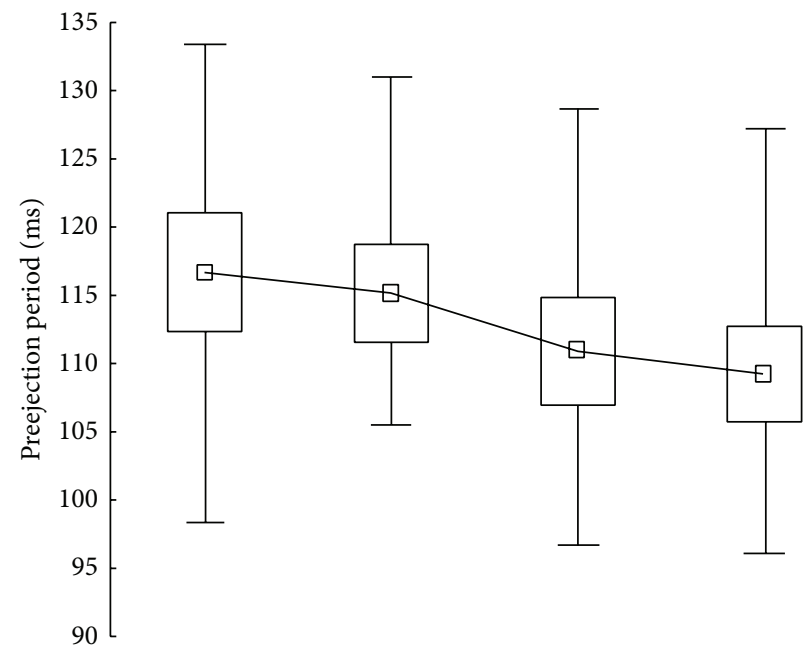

(d)

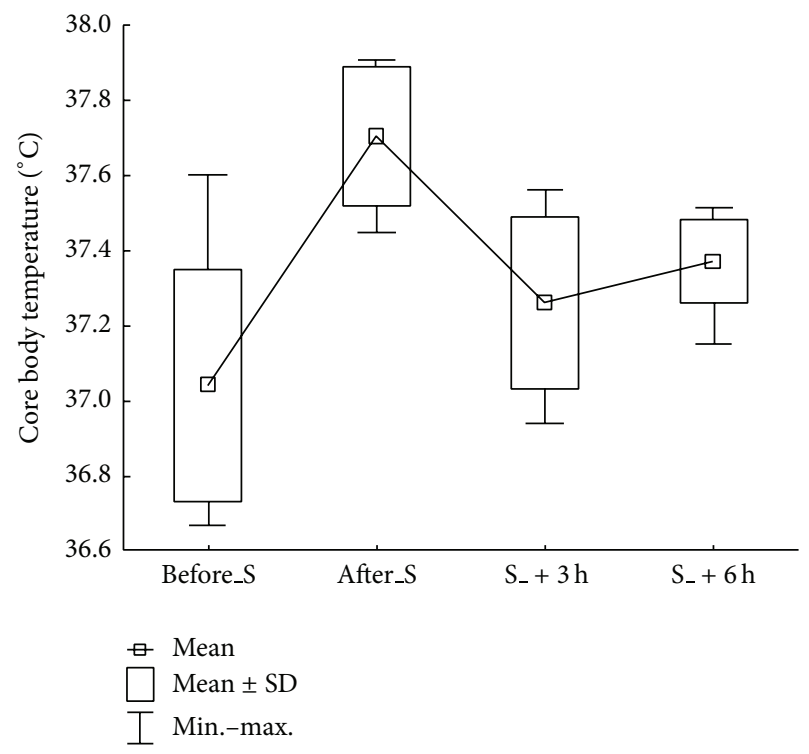

(f)

FIGURE 1: Relationships between hemodynamic and cardiovascular parameters and core body temperature at the specific stage of the experiment: before_S (before sauna), after_S (after sauna), $\mathrm{S}_{-}+3 \mathrm{~h}$ (3 hours after sauna), and $\mathrm{S}_{-}+6 \mathrm{~h}$ (six hours after sauna). (a) HR, (b) BRS, (c) LVET, (d) PEP, (e) HI, (f) core body temperature; (abbreviations are listed in the "Nomenclature" section). 


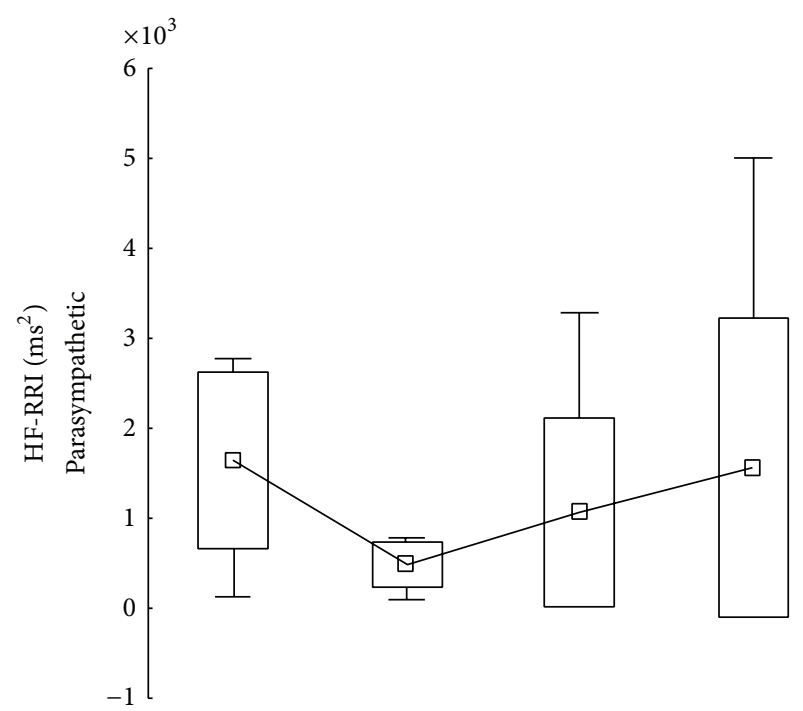

(a)

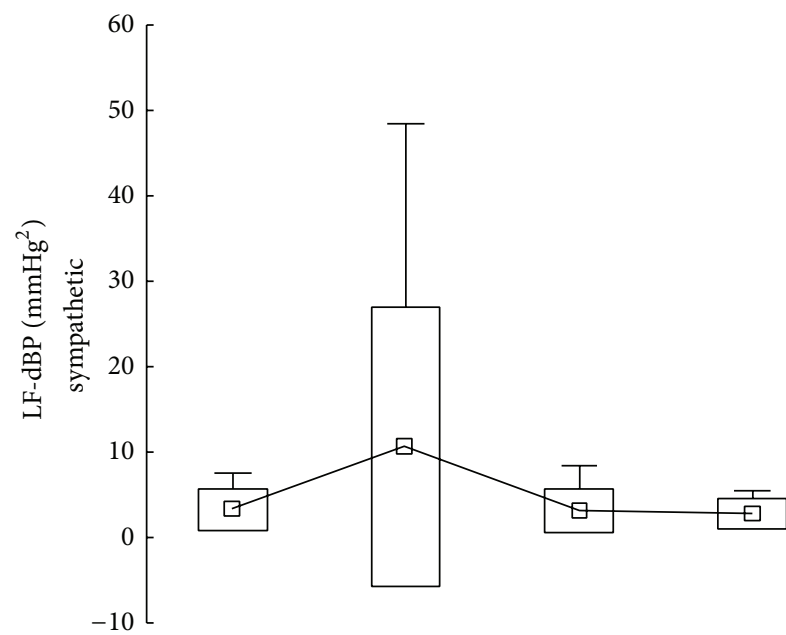

(c)

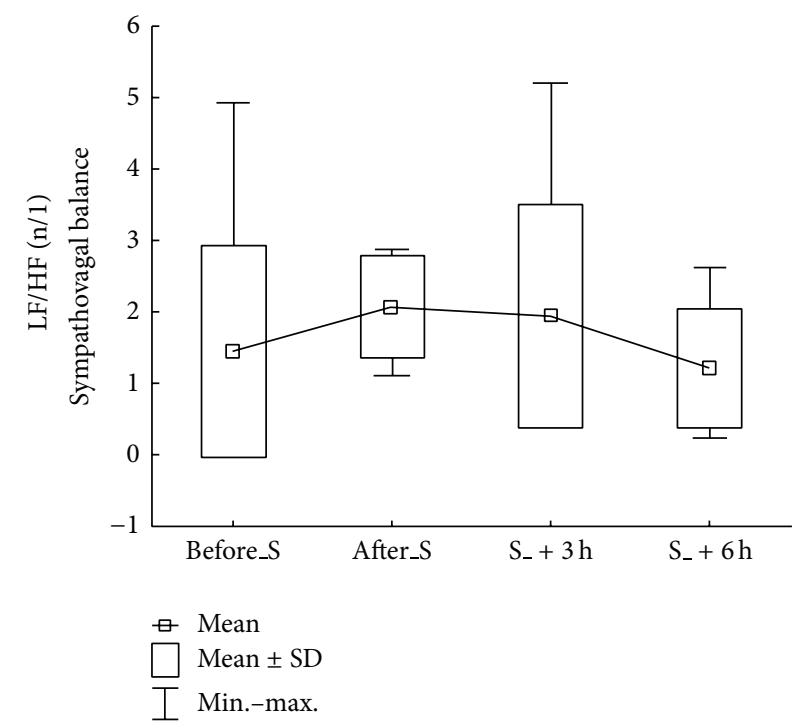

(e)

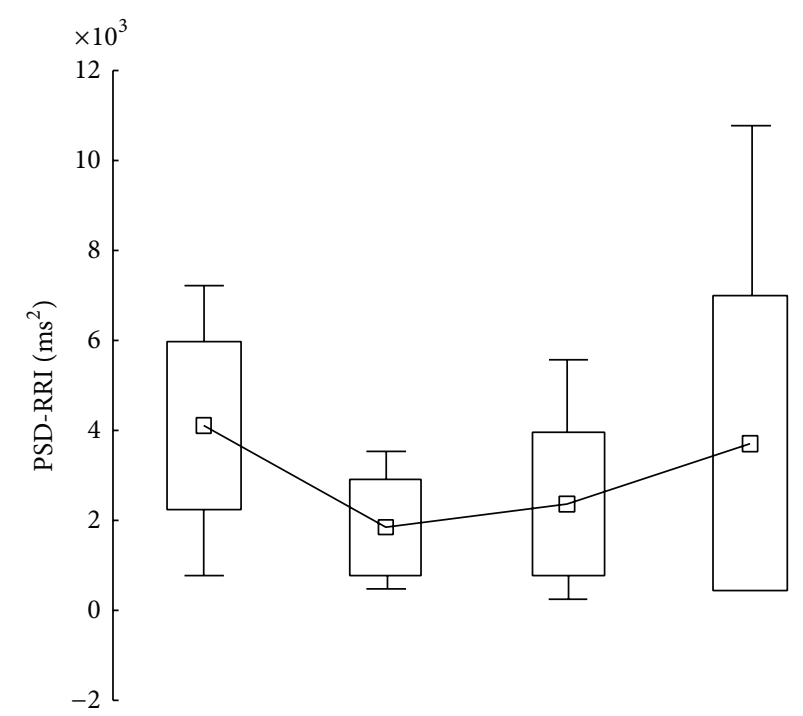

(b)

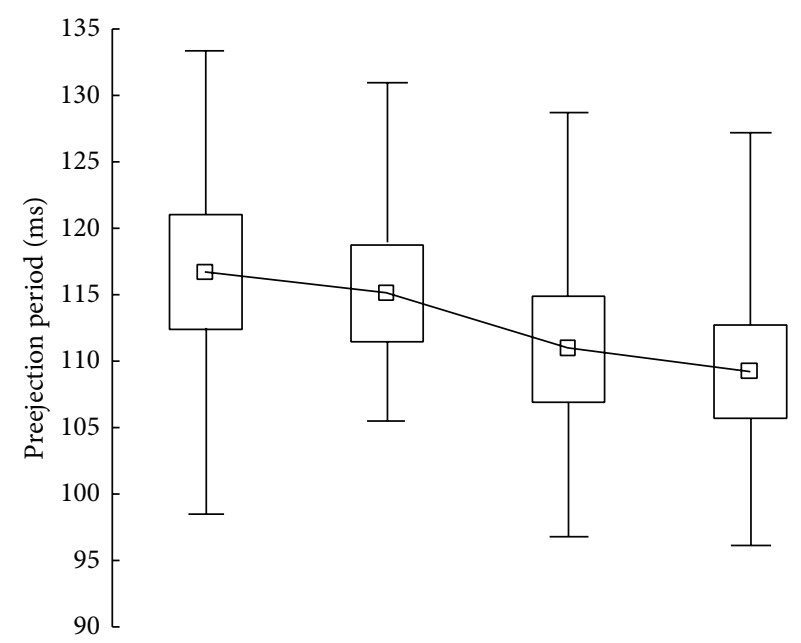

(d)

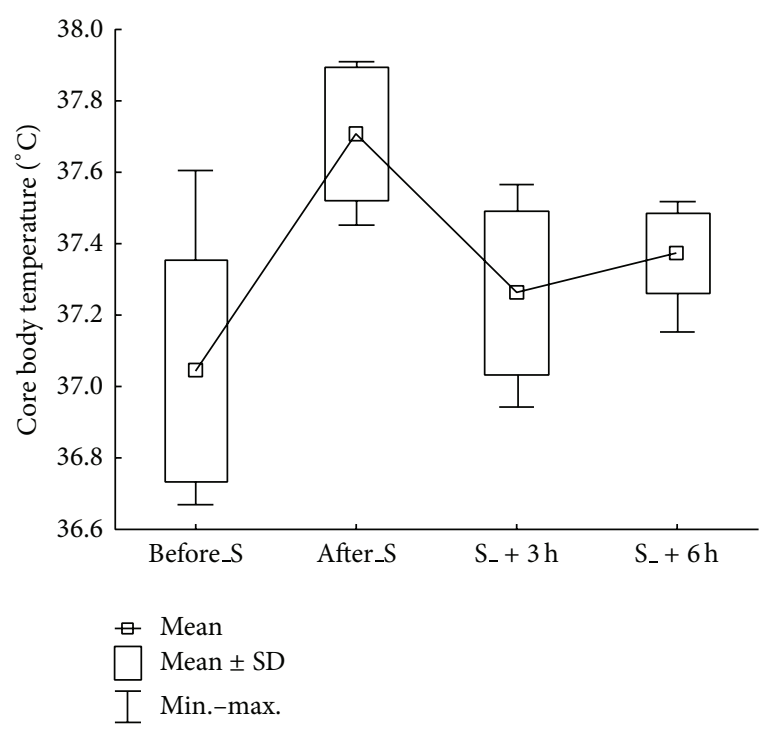

(f)

FIGURE 2: Relationships between heart rate and blood pressure variability parameters and core body temperature at the specific stage of the experiment: before_S (before sauna), after_S (after sauna), $S_{-}+3 \mathrm{~h}$ (3 hours after sauna), and $S_{-}+6 \mathrm{~h}$ (six hours after sauna). (a) HF-RRI, (b) PSD-RRI, (c) LF-dBP, (d) PSD-dBP, and (e) LF/HF; (abbreviations are listed in the "Nomenclature" section). 
TABLE 2: Resting values of basic cardiovascular and baroreceptor parameters in the study group; all data are expressed as means \pm standard deviations, and $P$ values (abbreviations are listed in the "Introduction" Section 1).

\begin{tabular}{|c|c|c|c|c|c|}
\hline Parameter & before_S & after_S & $\mathrm{S}_{-}+3 \mathrm{~h}$ & $\mathrm{~S}_{-}+6 \mathrm{~h}$ & $P$ \\
\hline $\mathrm{HR}(\mathrm{n} / 1)$ & $59.3 \pm 5.7$ & $65.0 \pm 7.2$ & $64.4 \pm 5.9$ & $59.9 \pm 5.2$ & $0.0120^{*}$ \\
\hline $\mathrm{sBP}(\mathrm{mmHg})$ & $127.9 \pm 8.7$ & $127.6 \pm 9.6$ & $129.9 \pm 13.4$ & $127.8 \pm 10.1$ & 0.7891 \\
\hline $\mathrm{dBP}(\mathrm{mmHg})$ & $78.9 \pm 5.9$ & $79.3 \pm 6.9$ & $78.6 \pm 8.5$ & $77 \pm 4.3$ & 0.7891 \\
\hline $\mathrm{mBP}(\mathrm{mmHg})$ & $94.5 \pm 8.4$ & $94.9 \pm 8.5$ & $93.9 \pm 10.5$ & $92.3 \pm 7.1$ & 0.6832 \\
\hline $\mathrm{TAC}(\mathrm{mL} / \mathrm{mmHg})$ & $2.3 \pm 0.4$ & $2.2 \pm 0.5$ & $2.3 \pm 0.6$ & $2.3 \pm 0.4$ & 0.9852 \\
\hline $\mathrm{SV}(\mathrm{mL})$ & $108.6 \pm 18.2$ & $104.7 \pm 20.7$ & $110.6 \pm 17.3$ & $113.2 \pm 13$ & 0.4663 \\
\hline $\mathrm{SI}\left(\mathrm{mL} / \mathrm{m}^{2}\right)$ & $54.0 \pm 8$ & $52.3 \pm 10.9$ & $55.3 \pm 9.4$ & $56.5 \pm 6.8$ & 0.4662 \\
\hline $\mathrm{EDI}\left(\mathrm{mL} / \mathrm{m}^{2}\right)$ & $89.2 \pm 11.8$ & $87.3 \pm 16.2$ & $90.6 \pm 14.6$ & $91.6 \pm 10.8$ & 0.5828 \\
\hline TFC (1/kOhm) & $36.5 \pm 2.6$ & $36.5 \pm 3$ & $37.8 \pm 3.4$ & $37.4 \pm 2.7$ & 0.0978 \\
\hline $\mathrm{CI}\left(\mathrm{L} / \mathrm{min} / \mathrm{m}^{2}\right)$ & $3.2 \pm 0.4$ & $3.4 \pm 0.6$ & $3.5 \pm 0.4$ & $3.4 \pm 0.4$ & 0.1271 \\
\hline $\mathrm{TPR}\left(\operatorname{dyn} * \mathrm{~s} * \mathrm{~m}^{2} / \mathrm{cm}^{5}\right)$ & $1180.8 \pm 193.7$ & $1130.1 \pm 232.2$ & $1051.6 \pm 172.7$ & $1093.2 \pm 212.6$ & 0.1241 \\
\hline TPRI $\left(\mathrm{dyn} * \mathrm{~s} * \mathrm{~m}^{2} / \mathrm{cm}^{5}\right)$ & $2369.3 \pm 404.9$ & $2283.8 \pm 544.2$ & $2112.6 \pm 360.3$ & $2186.5 \pm 378.7$ & 0.6533 \\
\hline $\mathrm{BRS}(\mathrm{ms} / \mathrm{mmHg})$ & $32.7 \pm 9.6$ & $21.8 \pm 7.2$ & $26.7 \pm 9.7$ & $30.3 \pm 14.7$ & $0.0457^{*}$ \\
\hline
\end{tabular}

* Indicates significantly different results; all parameters are expressed as mean \pm standard deviation.

TABLE 3: Resting values of ccontractility and heart muscle cycle parameters; all data are expressed as means \pm standard deviations, and $P$ values (abbreviations are listed in the "Introduction" Section 1).

\begin{tabular}{|c|c|c|c|c|c|}
\hline Parameter & before_S & after_S & $\mathrm{S}_{-}+3 \mathrm{~h}$ & $S_{-}+6 h$ & $P$ \\
\hline IC (1000/s) & $61 \pm 11.4$ & $61.5 \pm 17.8$ & $65.7 \pm 15.8$ & $66.1 \pm 12.7$ & 0.5221 \\
\hline $\operatorname{ACI}\left(100 / \mathrm{s}^{2}\right)$ & $80.5 \pm 13.8$ & $82.9 \pm 19.1$ & $87.9 \pm 18.8$ & $89.4 \pm 17.3$ & 0.1993 \\
\hline $\mathrm{HI}\left(1 / \mathrm{s}^{2}\right)$ & $0.34 \pm 0.11$ & $0.34 \pm 0.12$ & $0.41 \pm 0.17$ & $0.38 \pm 0.09$ & $0.0238^{*}$ \\
\hline LVET (ms) & $320.4 \pm 13$ & $305.1 \pm 12.9$ & $307.5 \pm 13.4$ & $314.7 \pm 13.7$ & $0.0181^{*}$ \\
\hline $\mathrm{PEP}(\mathrm{ms})$ & $116.7 \pm 12.1$ & $115.1 \pm 10.1$ & $111 \pm 11.2$ & $109.2 \pm 9.8$ & $0.0068^{*}$ \\
\hline STR $(\%)$ & $36.6 \pm 4.2$ & $37.9 \pm 3.6$ & $36.2 \pm 3.4$ & $34.8 \pm 3$ & 0.1116 \\
\hline LVWI $\left(\mathrm{mmHg} * \mathrm{~L} /\left(\min * \mathrm{~m}^{2}\right)\right)$ & $4.0 \pm 0.6$ & $4.2 \pm 0.7$ & $4.4 \pm 0.8$ & $4.1 \pm 0.6$ & 0.2260 \\
\hline
\end{tabular}

${ }^{*}$ Indicates significantly different results; all parameters are expressed as mean \pm standard deviation.

TABLE 4: Statistical characteristics of core body temperature at the each stage of the experiment.

\begin{tabular}{lcccc}
\hline Measurement & \multicolumn{4}{c}{ Core Body Temperature $\left[{ }^{\circ} \mathrm{C}\right]$} \\
$F=10.83 P<0.01$ & Mean & Minimum & Maximum & SD \\
\hline before_S & 37.0 & 36.7 & 37.6 & 0.32 \\
after_S & 37.7 & 37.5 & 37.9 & 0.21 \\
S $_{-}+3 \mathrm{~h}$ & 37.3 & 36.9 & 37.6 & 0.37 \\
$\mathrm{~S}_{-}+6 \mathrm{~h}$ & 37.4 & 37.2 & 37.5 & 0.18 \\
\hline
\end{tabular}

modulates their core body temperature and function of the cardiovascular and autonomic nervous systems. The principal aim of the study was to analyse the adaptation to such specific and extreme environmental conditions; thus, potential therapeutic effects of the Finnish sauna bath were addressed only indirectly. Moreover, the process of cooling down took place at an ambient temperature, without the use of cold water shower or immersion. Thus, our findings may differ markedly from the data published by other authors, who studied the effects of classic sauna [29].

Significantly disturbed thermal balance of the body, resulting from intensive heating of the skin and subcutaneous tissue due to enhanced perfusion thereof, is the principal initiator of cardiovascular changes. A number of authors showed that sauna treatment causes a considerable heating of external body layers; although the relative increase in superficial body temperature observed in various studies differed up to $1-2^{\circ} \mathrm{C}$, treatment in the sauna is undoubtedly reflected by an increase in physiological temperature of the skin and surrounding tissues $[29,30]$. We did not determine the superficial body temperatures of our participants, assuming that the characteristics of the thermal stimulus associated with the sauna bath were sufficient for intensive heating of the deeper tissues in the young healthy persons.

In contrast to the analyses of superficial temperature of the body, the studies dealing with dry sauna-induced changes in core body temperature are sparse. In most of these studies, rectal temperature or tympanic membrane temperature was used as a substitute of the core body temperature. Although the rectal temperature is strongly correlated with the core body temperature, its determination causes marked discomfort. In contrast, the tympanic membrane temperature can be determined easily and in a noninvasive manner but is considered an inaccurate and unreliable measure of the core body temperature.

A 15-minute exposure to dry sauna treatment was associated with a significant increase in the core body temperature 
TABLE 5: Resting values of heart rate and blood pressure variability parameters; all data are expressed as means \pm standard deviations, and $P$ values (abbreviations are listed in the "Introduction" Section 1).

\begin{tabular}{|c|c|c|c|c|c|c|}
\hline Parameter & & before_S & after_S & $\mathrm{S}_{-}+3 \mathrm{~h}$ & $\mathrm{~S}_{-}+6 \mathrm{~h}$ & $P$ \\
\hline \multirow{7}{*}{ Heart rate variability } & LFnu-RRI (\%) & $49.2 \pm 20.5$ & $62.6 \pm 15.4$ & $54.5 \pm 21.1$ & $51.1 \pm 21$ & 0.2406 \\
\hline & HFnu-RRI (\%) & $50.8 \pm 20.5$ & $37.4 \pm 15.4$ & $45.5 \pm 21.1$ & $48.9 \pm 21$ & 0.2406 \\
\hline & LF-RRI $\left(\mathrm{ms}^{2}\right)$ & $1587.9 \pm 1221.1$ & $1007.9 \pm 752.8$ & $931.6 \pm 500.9$ & $1569.4 \pm 1498.4$ & 0.5221 \\
\hline & HF-RRI $\left(\mathrm{ms}^{2}\right)$ & $1643.8 \pm 971.7$ & $493.6 \pm 247$ & $1068.7 \pm 1050.3$ & $1561.5 \pm 1665.6$ & $0.0313^{*}$ \\
\hline & PSD-RRI $\left(\mathrm{ms}^{2}\right)$ & $4058.3 \pm 1876.7$ & $1817.2 \pm 1069$ & $2331.3 \pm 1593.2$ & $3678.9 \pm 3266.9$ & $0.0412^{*}$ \\
\hline & LF/HF-RRI (n/1) & $1.6 \pm 1.9$ & $2.2 \pm 1.1$ & $2.2 \pm 2.2$ & $1.7 \pm 1.7$ & 0.1543 \\
\hline & $\mathrm{LF} / \mathrm{HF}(\mathrm{n} / 1)$ & $1.5 \pm 1.5$ & $2.1 \pm 0.7$ & $1.9 \pm 1.6$ & $1.2 \pm 0.8$ & $0.0483^{*}$ \\
\hline \multirow{6}{*}{$\begin{array}{l}\text { Diastolic blood pressure } \\
\text { variability }\end{array}$} & LFnu-dBP (\%) & $49.9 \pm 13.2$ & $65.4 \pm 11.9$ & $57.6 \pm 13.1$ & $44.2 \pm 21$ & $0.0438^{*}$ \\
\hline & HFnu-dBP (\%) & $15.3 \pm 10.4$ & $6.3 \pm 3.1$ & $13.4 \pm 11$ & $16.8 \pm 16.9$ & $0.0238^{*}$ \\
\hline & LF-dBP $\left(\mathrm{mmHg}^{2}\right)$ & $3.4 \pm 2.4$ & $10.8 \pm 16.2$ & $3.3 \pm 2.5$ & $2.9 \pm 1.7$ & 0.6822 \\
\hline & HF-dBP $\left(\mathrm{mmHg}^{2}\right)$ & $0.8 \pm 0.4$ & $0.7 \pm 0.9$ & $0.5 \pm 0.3$ & $1.1 \pm 1.4$ & $0.0433^{*}$ \\
\hline & PSD-dBP $\left(\mathrm{mmHg}^{2}\right)$ & $6.4 \pm 3.2$ & $20.2 \pm 35.6$ & $5.4 \pm 3.1$ & $6.7 \pm 2.8$ & 0.4663 \\
\hline & LF/HF-dBP (n/1) & $6.1 \pm 5.6$ & $13.2 \pm 6$ & $8.5 \pm 6.8$ & $5.6 \pm 5.1$ & $0.0029^{*}$ \\
\hline \multirow{6}{*}{$\begin{array}{l}\text { Systolic blood pressure } \\
\text { variability }\end{array}$} & LFnu-sBP (\%) & $43.8 \pm 12.8$ & $55.5 \pm 10.3$ & $47.2 \pm 17.1$ & $37.1 \pm 15.3$ & $0.0273^{*}$ \\
\hline & HFnu-sBP (\%) & $13.9 \pm 9.2$ & $10.6 \pm 6.8$ & $9.9 \pm 5.3$ & $15.4 \pm 12.6$ & 0.1993 \\
\hline & LF-sBP $\left(\mathrm{mmHg}^{2}\right)$ & $7.6 \pm 8.2$ & $13 \pm 16.1$ & $8.7 \pm 6.9$ & $5.9 \pm 6.5$ & 0.7173 \\
\hline & HF-sBP $\left(m m H g^{2}\right)$ & $2 \pm 2.5$ & $1.5 \pm 1$ & $1.9 \pm 1.8$ & $1.6 \pm 1.1$ & 0.6822 \\
\hline & PSD-sBP $\left(\mathrm{mmHg}^{2}\right)$ & $15.9 \pm 15$ & $26.5 \pm 37.6$ & $18 \pm 10.8$ & $16.1 \pm 14$ & 0.8964 \\
\hline & LF/HF-sBP (n/1) & $4.5 \pm 2.9$ & $8.3 \pm 5.4$ & $6.0 \pm 3.5$ & $4.3 \pm 4.5$ & $0.0439^{*}$ \\
\hline
\end{tabular}

${ }^{*}$ Indicates significantly different results; all spectral parameters are expressed as mean \pm standard deviation.

of examined individuals. This finding seems important in the context of resultant functional changes in the cardiovascular and autonomic nervous system. Intensive heating of the skin and resultant increase in core body temperature were associated with an array of hemodynamic changes that could be observed up to 6 hours after the thermal treatment.

Previous studies have shown that intensive heating of the skin may be reflected by an increase in dermal perfusion, from $300-400 \mathrm{~mL} / \mathrm{min}$ up to $6000-7500 \mathrm{~mL} / \mathrm{min}[29,30]$; such marked decentralization of the blood and the necessity to maintain appropriate cerebral perfusion undoubtedly result in severe alterations of the body haemodynamics. The principal regulatory mechanisms in body haemodynamics are controlled by the autonomic nervous system. Consequently, the synchronic analysis of basic cardiovascular, hemodynamic, and contractility parameters, myocardial strain, blood pressure and heart rate variability, and their association with the changes of core body temperature enabled us to study the dynamics of the compensatory processes activated in response to overheating.

The significant increase in heart rate (HR) of our participants and subsequent gradual normalization of this parameter with a decrease in core body temperature are a wellestablished response to passive heating of the body. This mechanism is vital for maintaining normal perfusion of cerebral vessels, despite a decrease in venous return and stroke volume (SV). The abovementioned changes were associated with an increase in cardiac output (CO), which remained elevated up to 3 hours postexposure, that is, until gradual normalization of heart rate and venous return, associated with progressive cooling down of the skin $[19,30]$.

Immediately after the exposure, our participants showed a decrease in the values of systolic index, end-diastolic index (EDI), and stroke volume. A gradual increase in these parameters was observed 3 and 6 hours postexposure. The changes of stroke volume probably resulted from an initial decrease in venous return caused by an enhanced perfusion of the skin during its maximum heating. A gradual loss of heat was reflected by a progressive increase in venous return and resultant increase in stroke volume, which eventually reached higher values than those prior to the exposure. While the temperature-induced changes of volumetric myocardial parameters did not prove to be significant on statistical analysis, we observed significant changes in the values of ejection time characteristics, that is, left ventricular ejection time and preejection period. Initial decrease and subsequent gradual increase in venous return were reflected by synchronised changes of left ventricular ejection time (LVET) and preejection period (PEP); this resulted in gradual changes in the cardioimpedance parameters of myocardial contractility. Although both the index of contractility (IC) and the acceleration index (ACI) increased with time after exposure, none of these changes proved to be significant on statistical analysis. Heather index (HI) turned out to be the only contractility parameter which showed significant alterations in response to the thermal treatment. We would suggest that this reflected higher sensitivity of this parameter to changes in myocardial inotropy $[19,29]$. The abovementioned 
findings are consistent with the Frank-Starling law, according to which an increase in venous return is reflected by a greater filling of heart chambers, an increase in preload, and a resultant positive inotropic effect. However, these changes were documented 3 and 6 hours postexposure, thus confirming the findings of other authors who showed that maximum heating of the body is not associated with an increase in myocardial contractility. This phenomenon is explained as a consequence of decreased venous return and resultant decreased filling of heart chambers [4]. Increased heart rate and positive inotropic effect would cause an increase in blood pressure under normothermic conditions; however, a decreased peripheral resistance after the thermal exposure (resulting from a decrease in venous return and afterload) was reflected by stable and safe levels of blood pressure and arterial compliance. Moreover, we showed that intensive heating was not reflected by an impairment of myocardial performance parameters or an increase in an "oxygen debt" of cardiomyocytes. These observations are consistent with the results of previous studies and may at least partially confirm the positive effect of sauna treatment on the cardiovascular system $[4,29]$.

Responses to thermal stimulation are under tight control by the autonomic nervous system. The exposure of our participants to intensive thermal stimulus was reflected by a decrease in HF-RRI component. This corresponded to a decrease in parasympathetic response and baroreceptor reflex sensitivity. The postexposure decrease in power spectral density (PSD-RRI) was associated mostly with the change of HF-RRI component and also corresponded to the increase in sympathetic-parasympathetic balance ratio (LF/HF). Interestingly, a significant increase in power spectral density of LFRRI and HF-RRI was observed 3 and 6 hours postexposure, along with a normalization of the $\mathrm{LF} / \mathrm{HF}$ ratio. Also the results of the spectral analysis of blood pressure variability, namely, an increase in the normalized low-frequency components of sBP (LFnu-sBP) and dBP (LFnu-sBP) spectra and a concomitant decrease in the normalized high-frequency component of $\mathrm{dBP}$ spectrum (HFnu-dBP), confirmed the sympathetic predominance after thermal stimulation. The increased sympathetic activity was associated with enhanced thermogenesis, which is consistent with the data published by other authors [31, 32].

The analysis of baroreceptor reflex sensitivity (BRS) confirmed that intensive heating of the body causes a significant decrease in the latter parameter. This might reflect a direct influence of the thermal stimulus on the hypothalamic thermoregulatory centre (containing nuclei responsible for the control the baroreceptor function) and potential central inhibition of the baroreceptor reflex. However, most previous studies have revealed that intensive heating of the body does not alter the baroreceptor reflex sensitivity. Only one study has shown that the temperature-induced changes of heart rate and blood pressure resulted from a decreased vagal activity and an increased sympathetic activity, caused by the baroreceptor reflex inhibition. Also, the abovementioned hemodynamic changes, leading to a decreased filling of the carotid bulbs and aortic arch, could constitute a potential mechanism behind altered baroreceptor reflex sensitivity. However, on the basis of our findings, one cannot unambiguously identify which of the mechanisms played the predominant role in the abovementioned process. Nevertheless, the lack of significant changes in blood pressure may point to a greater involvement of the hemodynamic component [32-36].

In conclusion, this study has revealed that exposure to the extreme external environmental conditions of dry sauna does not compromise homeostasis in healthy persons. The hemodynamic changes induced by heating are efficiently compensated by the cardiovascular system and do not exert negative effects upon its short-term regulatory potential.

\section{Limitations}

The small number of the participants and lack of any skin temperature data are significant limitations in this study. Also, we did not consider the potential influence of respiratory rate on blood pressure and heart rate variability. It undoubtedly decreased the power of statistical tests and was reflected by a lack of statistical significance in the case of some evidently decreasing or increasing trends. However, these potential flaws are likely counterbalanced by the coherent and complementary character of our findings.

\section{Nomenclature}

$\begin{array}{ll}\text { ANS: } & \text { Autonomic nervous system } \\ \text { BPV: } & \text { Blood pressure variability } \\ \text { BRS: } & \text { Baroreceptor reflex sensitivity } \\ \text { BSA: } & \text { Body surface area } \\ \text { CI: } & \text { Cardiac index } \\ \text { CO: } & \text { Cardiac output } \\ \text { dBP: } & \text { Diastolic blood pressure } \\ \text { dBPV: } & \text { Diastolic blood pressure variability } \\ \text { EDI: } & \text { End-diastolic index } \\ \text { ER: } & \text { Early ejection } \\ \text { HF: } & \text { High-band frequency spectrum } \\ \text { HF-dBP: } & \text { HF-component of dBPV } \\ \text { HFnu-dBP: } & \text { Normalized "HF-component" of dBPV } \\ \text { HFnu-RRI: } & \text { Normalized "HF-component" of HRV } \\ \text { HFnu-sBP: } & \text { Normalized "HF-component" of sBPV } \\ \text { HF-RRI: } & \text { HF-component of HRV } \\ \text { HF-sBP: } & \text { HF-component of sBPV } \\ \text { HR: } & \text { Heart rate } \\ \text { HRV: } & \text { Heart rate variability } \\ \text { IC: } & \text { Index of contractility } \\ \text { LF: } & \text { Low-band frequency spectrum } \\ \text { LF/HF: } & \text { Sympathovagal balance LF-dBPV/HF-RRI } \\ \text { LF/HF-dBP: } & \text { LF/HF ratio of dBPV } \\ \text { LF/HF-sBP: } & \text { LF/HF ratio of sBPV } \\ \text { LF-dBP: } & \text { LF-component of dBPV } \\ \text { LFnu-dBP: } & \text { Normalized "LF-component" of dBPV } \\ \text { LFnu-RRI: } & \text { Normalized "LF-component" of HRV } \\ \text { LFnu-sBP: } & \text { Normalized "LF-component" of sBPV } \\ \text { LF-RRI: } & \text { LF-component of HRV } \\ \text { LF-sBP: } & \text { LF-component of sBPV } \\ \text { LVET: } & \text { Left ventricular-ejection time } \\ & \end{array}$


mBP: $\quad$ Mean blood pressure

PEP: $\quad$ Aortic preejection period

PSD-dBPV: Power spectral density of dBPV

PSD-RRI: Power spectral density of HRV

PSD-sBPV: Power spectral density of sBPV

sBP: $\quad$ Systolic blood pressure

sBPV: $\quad$ Systolic blood pressure variability

SI: $\quad$ Stroke index

SV: $\quad$ Stroke volume

TFC: $\quad$ Thoracic fluid content

TFM: $\quad$ Task force monitor

TPR: $\quad$ Total peripheral resistance

TPRI: Total peripheral resistance index.

\section{Conflict of Interests}

The authors declare that there is no conflict of interests regarding the publication of this paper.

\section{References}

[1] R. Beever, "Far-infrared saunas for treatment of cardiovascular risk factors: summary of published evidence," Canadian Family Physician, vol. 55, no. 7, pp. 691-696, 2009.

[2] A. Kenttämies and K. Karkola, "Death in sauna," Journal of Forensic Sciences, vol. 53, no. 3, pp. 724-729, 2008.

[3] P. Valtakari, "The sauna and bathing in different countries," Annals of Clinical Research, vol. 20, no. 4, pp. 230-235, 1988.

[4] T. Kihara, S. Biro, Y. Ikeda et al., "Effects of repeated sauna treatment on ventricular arrhythmias in patients with chronic heart failure," Circulation Journal, vol. 68, no. 12, pp. 1146-1151, 2004.

[5] M. Imamura, S. Biro, T. Kihara et al., "Repeated thermal therapy improves impaired vascular endothelial function in patients with coronary risk factors," Journal of the American College of Cardiology, vol. 38, no. 4, pp. 1083-1088, 2001.

[6] M. L. Keast and K. B. Adamo, "The Finnish sauna bath and its use in patients with cardiovascular disease," Journal of Cardiopulmonary Rehabilitation, vol. 20, no. 4, pp. 225-230, 2000.

[7] W. J. Crinnion, "Sauna as a valuable clinical tool for cardiovascular, autoimmune, toxicant-induced and other chronic health problems," Alternative Medicine Review, vol. 16, no. 3, pp. 215225, 2011.

[8] E. Ahonen and U. Nousiainen, "The sauna and body fluid balance," Annals of Clinical Research, vol. 20, no. 4, pp. 257-261, 1988.

[9] K. Kauppinen, "Facts and fables about sauna," Annals of the New York Academy of Sciences, vol. 813, pp. 654-662, 1997.

[10] S. Biro, A. Masuda, T. Kihara, and C. Tei, "Clinical implications of thermal therapy in lifestyle-related disease," Experimental Biology and Medicine, vol. 228, no. 10, pp. 1245-1249, 2003.

[11] A. Masuda, Y. Koga, M. Hattanmaru, S. Minagoe, and C. Tei, "The effects of repeated thermal therapy for patients with chronic pain," Psychotherapy and Psychosomatics, vol. 74, no. 5, pp. 288-294, 2005.

[12] A. Masuda, T. Kihara, T. Fukudome, T. Shinsato, S. Minagoe, and C. Tei, "The effects of repeated thermal therapy for two patients with chronic fatigue syndrome," Journal of Psychosomatic Research, vol. 58, no. 4, pp. 383-387, 2005.
[13] M. L. Hannuksela and S. Ellahham, "Benefits and risks of sauna bathing," The American Journal of Medicine, vol. 110, no. 2, pp. 118-126, 2001.

[14] O. J. Luurila, "Cardiac arrhythmias, sudden death and the Finnish sauna bath," Advances in Cardiology, vol. 25, pp. 73-81, 1978.

[15] T. Kihara, S. Biro, M. Imamura et al., "Repeated sauna treatment improves vascular endothelial and cardiac function in patients with chronic heart failure," Journal of the American College of Cardiology, vol. 39, no. 5, pp. 754-759, 2002.

[16] H. Miyamoto, H. Kai, H. Nakaura et al., "Safety and efficacy of repeated sauna bathing in patients with chronic systolic heart failure: a preliminary report," Journal of Cardiac Failure, vol. 11, no. 6 , pp. 432-436, 2005.

[17] Y. Sugahara, M. Ishii, H. Muta, K. Egami, T. Akagi, and T. Matsuishi, "Efficacy and safety of thermal vasodilation therapy by sauna in infants with severe congestive heart failure secondary to ventricular septal defect," The American Journal of Cardiology, vol. 92, no. 1, pp. 109-113, 2003.

[18] J. Fortin, T. Klinger, C. Wagne, H. Sterne, C. Madritsch, and R. Grüllenberger, "The task force monitor-a non-invasive beatto-beat monitor for hemodynamic and autonomic function of the human body," in Proceedings of the 20th Annual International Conference of the IEEE Engineering in Medicine and Biology Society, Hong Kong, October-November 1988.

[19] C. G. Crandall and J. González-Alonso, "Cardiovascular function in the heat-stressed human," Acta Physiologica, vol. 199, no. 4, pp. 407-423, 2010.

[20] J. Fortin, W. Marte, R. Grüllenberger et al., "Continuous non-invasive blood pressure monitoring using concentrically interlocking control loops," Computers in Biology and Medicine, vol. 36, no. 9, pp. 941-957, 2006.

[21] G. Parati, M. DiRienzo, and G. Mancia, "How to measure baroreflex sensitivity: from the cardiovascular laboratory to daily life," Journal of Hypertension, vol. 18, no. 1, pp. 7-19, 2000.

[22] A. Malliani, F. Lombardi, and M. Pagani, "Power spectrum analysis of heart rate variability: a tool to explore neural regulatory mechanisms," British Heart Journal, vol. 71, no. 1, pp. $1-2,1994$.

[23] "Heart rate variability. Standards of measurement, physiological interpretation, and clinical use. Task Force of the European Society of Cardiology and the North American Society of Pacing and Electrophysiology," European Heart Journal, vol. 17, no. 3, pp. 354-381, 1996.

[24] G. Parati, S. Omboni, A. Frattola, M. Di Rienzo, A. Zanchetti, and G. Mancia, "Dynamic evaluation of the baroreflex in ambulant subject," in Blood Pressure and Heart Rate Variability, M. di Rienzo, G. Parati, A. Pedotti, and A. Zanchetti, Eds., pp. 123-137, IOS Press, 1992.

[25] R. Freeman, "Assessment of cardiovascular autonomic function," Clinical Neurophysiology, vol. 117, no. 4, pp. 716-730, 2006.

[26] "Assessment: clinical autonomic testing report of the Therapeutics and Technology Assessment Subcommittee of the American Academy of Neurology," Neurology, vol. 46, no. 3, pp. 873-880, 1996.

[27] V. Patel, S. Giesebrecht, A. R. Burton et al., "Reliability revisited: autonomic responses in the context of everyday well-being," International Journal of Cardiology, vol. 166, no. 3, pp. 743-745, 2013.

[28] P. Wust, C. H. Cho, B. Hildebrandt, and J. Gellermann, “Thermal monitoring: invasive, minimal-invasive and non-invasive 
approaches," International Journal of Hyperthermia, vol. 22, no. 3, pp. 255-262, 2006.

[29] M. Gayda, F. Paillard, P. Sosner et al., "Effects of sauna alone and postexercise sauna bats on blood pressure and hemodynamic variables in patients with untreated hypertension," Journal of Clinical Hypertension, vol. 14, no. 8, pp. 553-560, 2012.

[30] A. Sawlcka, T. Brzostek, and R. Kowalski, "Effects of sauna bath on the cardiovascular system," Medical Rehabilitation, vol. 11, no. 1, pp. 15-22, 2007.

[31] J. Cui, M. Sathishkumar, T. E. Wilson, M. Shibasaki, S. L. Davis, and C. G. Crandall, "Spectral characteristics of skin sympathetic nerve activity in heat-stressed humans," The American Journal of Physiology-Heart and Circulatory Physiology, vol. 290, no. 4, pp. H1601-H1609, 2006.

[32] F. Yamazaki and R. Sone, "Thermal stress modulates arterial pressure variability and arterial baroreflex response of heart rate during head-up tilt in humans," European Journal of Applied Physiology, vol. 84, no. 4, pp. 350-357, 2001.

[33] C. G. Crandall, "Heat stress and baroreflex regulation ofblood pressure," Medicine and Science in Sports and Exercise, vol. 40, no. 12, pp. 2063-2070, 2008.

[34] F. Yamazaki and R. Sone, "Modulation of arterial baroreflex control of heart rate by skin cooling and heating in humans," Journal of Applied Physiology, vol. 88, no. 2, pp. 393-400, 2000.

[35] F. Yamazaki and R. Sone, "Whole-body heating slows carotid baroreflex response in human subjects," European Journal of Applied Physiology, vol. 94, no. 5-6, pp. 690-696, 2005.

[36] F. Yamazaki, K. Yamauchi, Y. Tsutsui, Y. Endo, S. Sagawa, and K. Shiraki, "Whole body heating reduces the baroreflex response of sympathetic nerve activity during Valsalva straining," Autonomic Neuroscience: Basic and Clinical, vol. 103, no. 1-2, pp. $93-$ 99, 2003. 

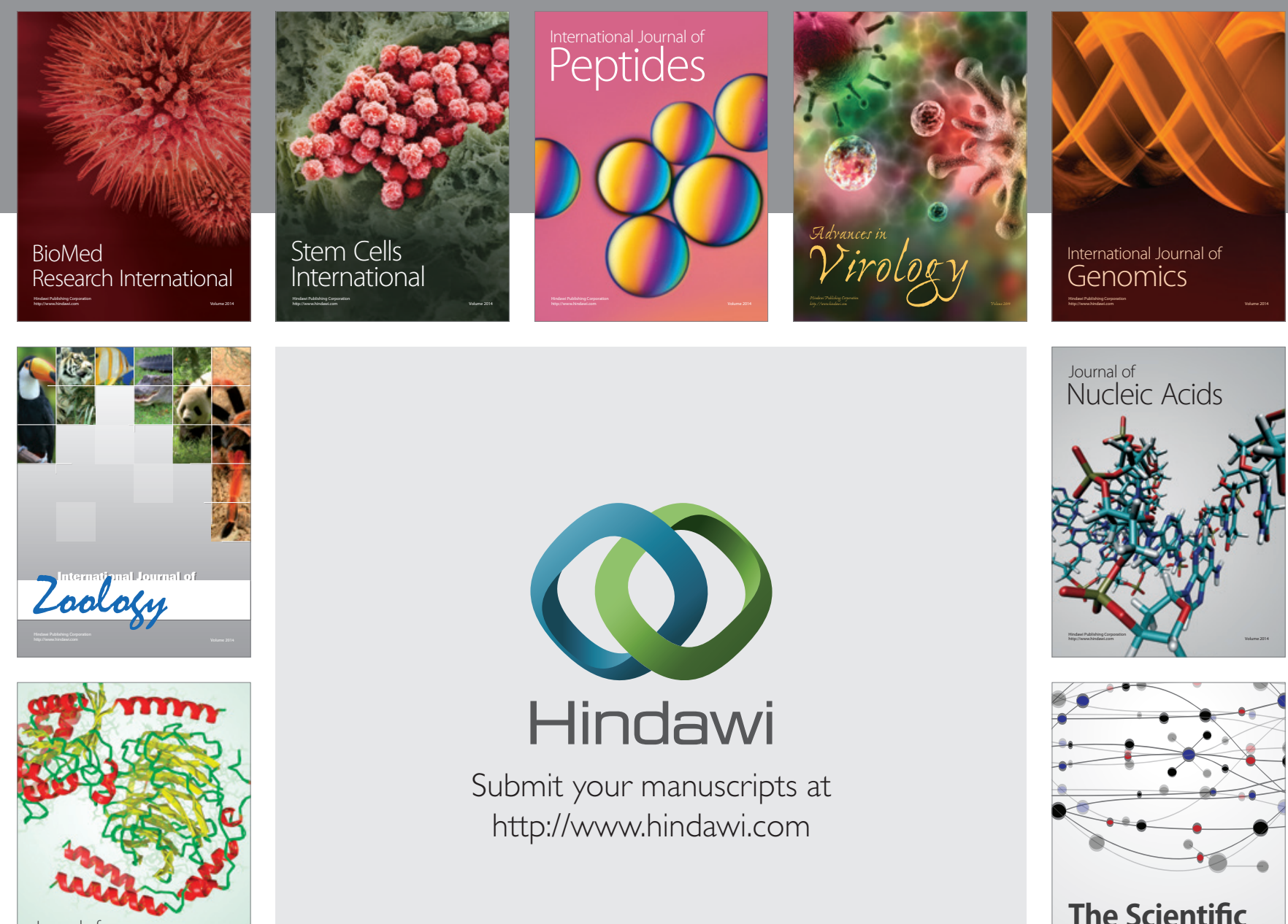

Submit your manuscripts at

http://www.hindawi.com

Journal of
Signal Transduction
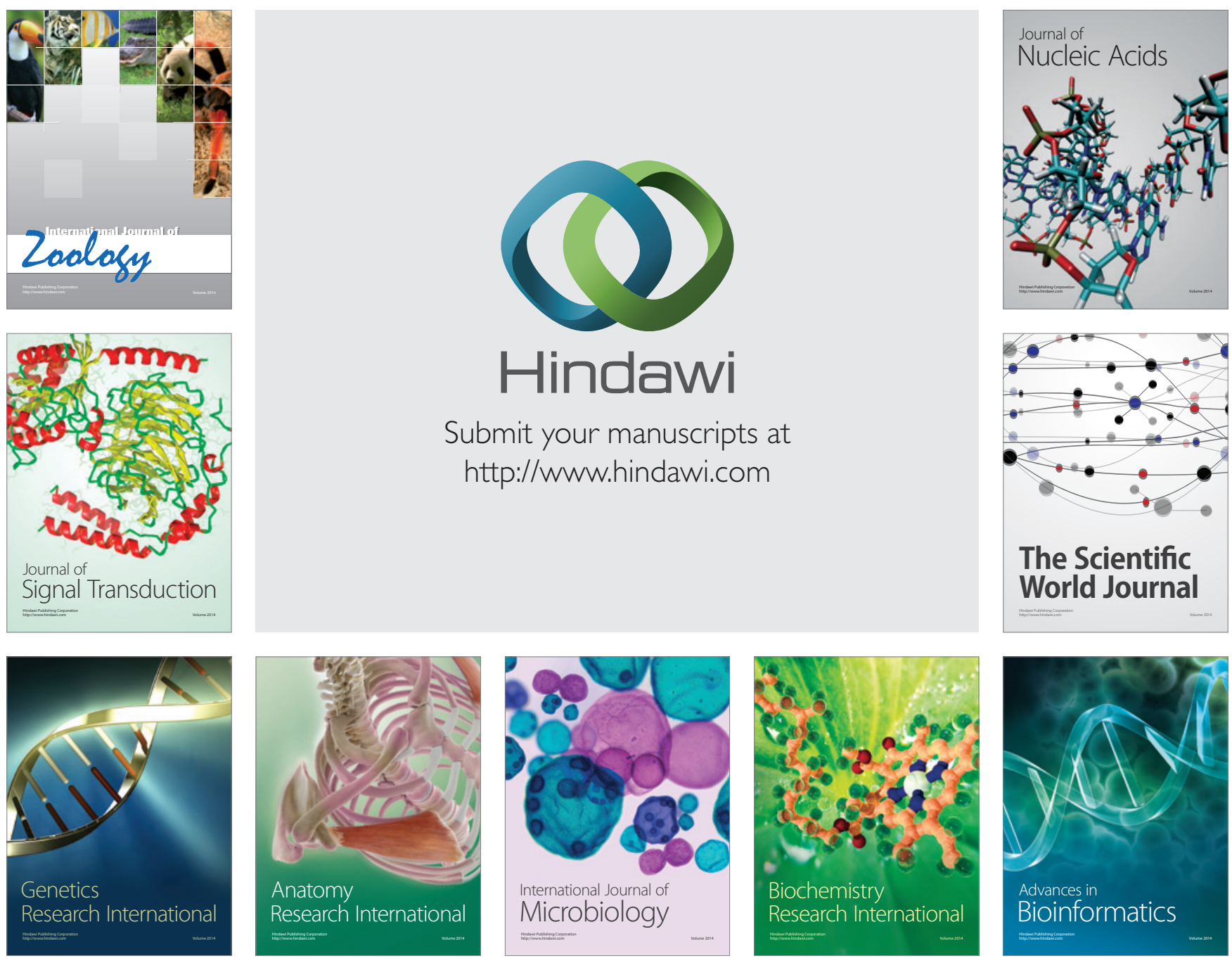

The Scientific World Journal
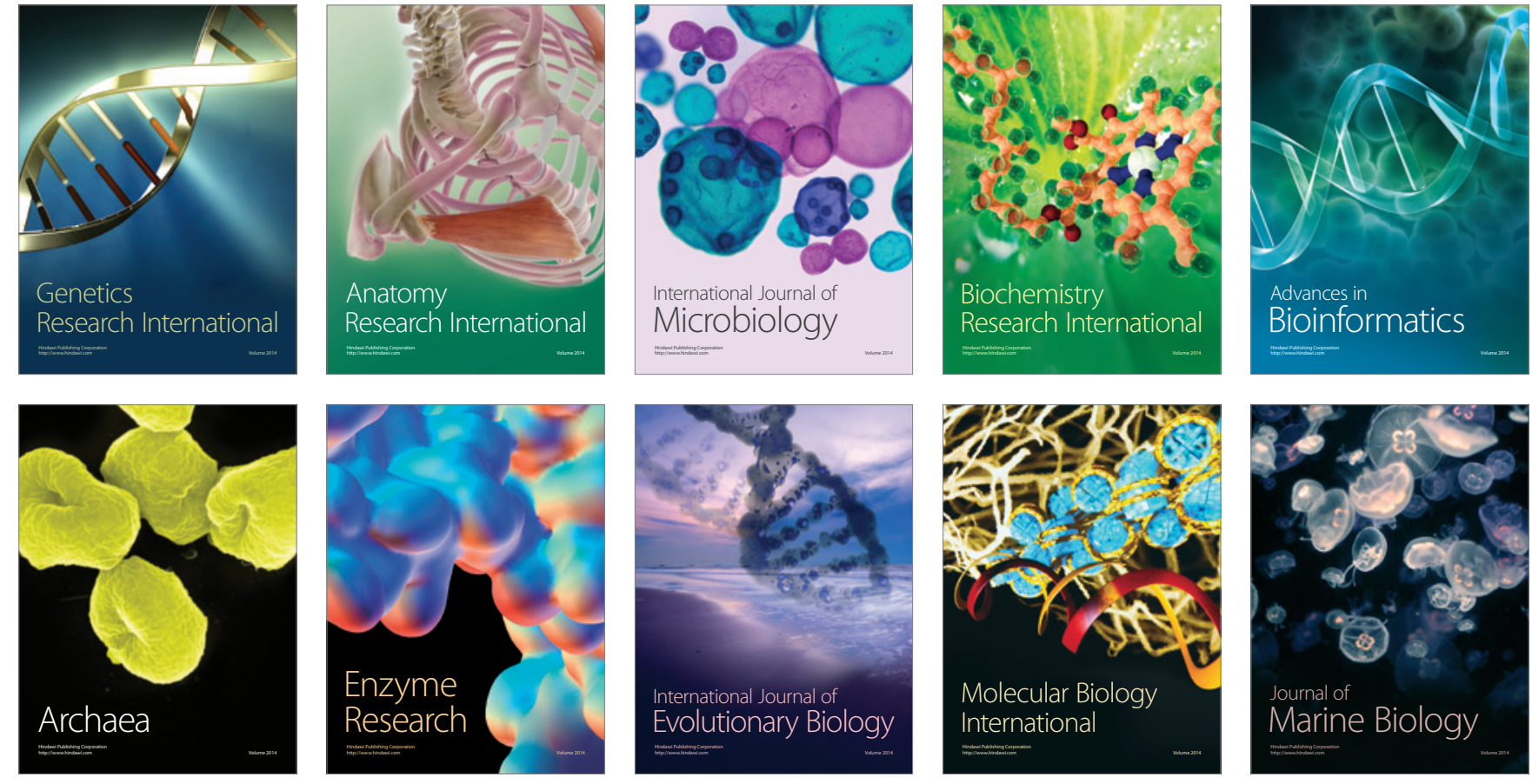